\title{
Enigmatic E-Cat of Andrea Rossi and the Unitary Quantum Theory
}

\author{
Leo G. Sapogin'1, Vladimir A. Dzhanibekov², Yuri A. Ryabov ${ }^{3}$ \\ ${ }^{1}$ Department of Physics, Technical University (MADI), Moscow, Russia \\ ${ }^{2}$ Department of Cosmophysics, Tomsk State University, Tomsk, Russia \\ ${ }^{3}$ Department of Mathematics, Technical University (MADI), Moscow, Russia \\ Email: sapogin@cnf.madi.ru,vdzhan42@yandex.ru, yuaryabov@gmail.com
}

Received 17 June 2016; accepted 24 July 2016; published 28 July 2016

Copyright (C) 2016 by authors and OALib.

This work is licensed under the Creative Commons Attribution International License (CC BY). http://creativecommons.org/licenses/by/4.0/

(c) (i) Open Access

\begin{abstract}
In this article we are discussing the nature and mechanism of the huge amount of heat generation in Megawatts Energy Catalyzers (E-cat) of Andrea Rossi that are able to change the energetics of our civilization in general. These processes are new effects of Unitary Quantum Theory and do not relate to either chemical or nuclear reactions or phase transfer.
\end{abstract}

\section{Keywords}

\section{E-Cat, Nickel Powder, Heterogeneous Catalysis, Quantum Harmonic Oscillator, Unitary Quantum Mechanics}

Subject Areas: Modern Physics

Today the science world is agitated by E-Cat of Andrea Rossi that is simply a pressurized ceramic tube with the nickel powder and Hydrogen inside. Under current this tube warms up and generates heat 3 - 50 times more than consumes. And as we are speaking about Megawatts any manipulation is hardly possible. Few official scientific commissions have concluded that nuclear reactions cannot generate such amount of energy. And even the isotopic composition of Nickel remains stable and heat generation looks absolutely mysterious that does not impede the using of these energy catalyzes.

This great technically implemented idea has long history. In 1983 one of the authors (L.S.) published first article in Russian popular science magazine (The Technics for a Yang) and described in plain language the new Unitary Quantum Theory of the World-UQT. According to this UQT [1]-[4] the particle was not a point (we can say nothing intelligible about a pointeven want to), but it was a bunch (a wave packet) of some unitary field. During his movement this wave packet periodically appears and disappears at de Broglier length wave. Schroedinger and Dirac equations are derived from this theory [5]. At the same time the UQT has an equation with 
oscillating charge [6] for individual particle that perfectly describes nearly every quantum effect and predicts the possibility of low-energy nuclear reactions existence, as well as some absolutely new effects resulting from new solutions for quantum oscillator. It's interesting but the editors have delayed every statement about possibility of nuclear reactions at low energies from the text of this article and the author has to return this information during galley proof. Six years later in the 1989 Fleischmann and Pons were conducting electrolysis of heavy water on the surface of a palladium coil and generated an anomalous heat. Fleischmann and Pons understood that chemical reactions on palladium could not be responsible for such heat effects and they announced the presence of $\mathrm{D}+\mathrm{D}$ nuclear reactions in their experiments. But other Nuclear Physicists neglected heat effects; they rushed into determination of microscopic products of nuclear reactions that could not be responsible for heat generation. Fleischmann and Pons were declared swindlers, moreover they had to emigrate. In 1995 one of the authors (L.S.) met Mr. Fleischmann in Monte-Carlo and asked him 2 questions:

1) Did they try to conduct electrolysis on palladium in common water and did the excess heat generation retain? His reply was positive. It makes clear that in this situation nuclear reactions should be eliminated.

2) What had happened to palladium after experiment? The reply was that it reduced to the finest powder.

Then the situation became more interesting. The thermal cell CETI (created by James Patterson in 1995), using electrolyze of specially manufactured nickel bolls in common water, had shocked scientists in USA. American newspaper "Fortean Times" No 85, 1995, wrote about it: "December the $4^{\text {th }}, 1995$ will go down to history!" At that day the group of independent experts from five American Universities tested the work of new energy source with stable output heat rating 1.3 KWatt. The electric energy input was 960 times less.” All experts noted that generated heat had enigmatic origin and would be explained neither by chemical or nuclear reactions nor by phase transfer. By American ABC TV there were two telecasts at $7^{\text {th }}$ and $8^{\text {th }}$ of February, 1996 in cycles "Nightline" and "Good Morning America" about Patterson creation of new source of energy, able to generate in hundred times more energy than it had consumed. And again it were accentuated that the origin of generated heat remains mysterious.

In terms of UQT [1]-[7] this thermal effect is able because the Conservation Laws appear only after averaging of particles' ensemble. Conservation Laws do not work for single particles at all and the character of their behavior depends on initial phase of the wave function that is never taken into consideration by standard quantum mechanics.

Equation with oscillating charge is the same Newton equation for the charge movement in external potential, where charge value depends on time, velocity and coordinates [5]-[7]. Two new solutions called "Crematorium" and "Maternity Home" (Figure 1) appear during harmonic oscillator problem solving in addition to standard stationary solutions.

In the first solution a particle oscillates in potential well with exponential decrease of energy, in the second its energy increases (infinitely for parabolic well). Grains of Nickel (it could be grains or finest crystals) in E-cat have caverns with size of tens Angstroms (they work as potential wells); proton of adequate phase can penetrate inside a cavern. Heat is generated in these caverns under terms of "Maternity Home" as the result of protons numerous knocks on cavern's walls.

The scenarios of these processes depend on the wave function phase, geometry of cavern, time, coordinate and velocity of proton. It's clear that in the result of protons' knocks the small grains of Nickel are milled to finest powder. Apparently catalyst degradation or even termination of it activity in time are result of caverns

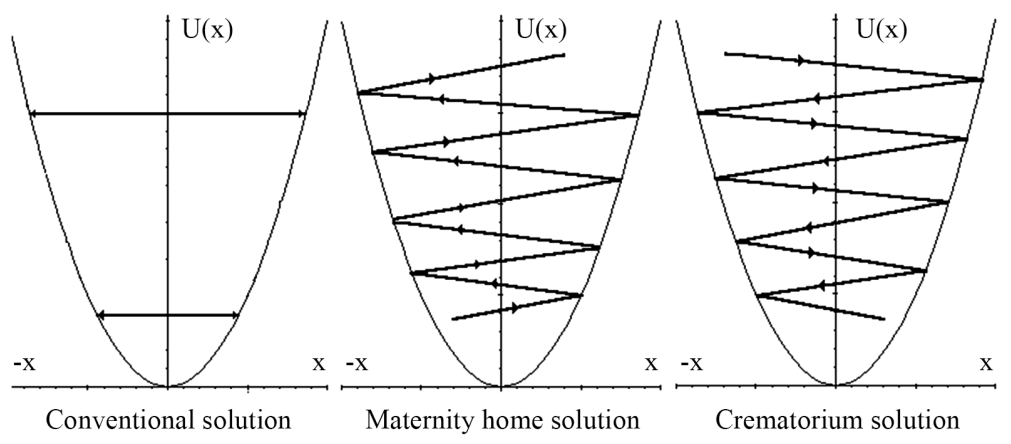

Figure 1. Solution for quantum harmonic oscillators in UQT. 
destruction but chemists call it "catalyst poisoning”. Of course poisoning can occur if any foreign atom sticks in cavern.

Absolutely the same scenario we have for Nitrogen in production of Ammonia. At standard terms molecular of Nitrogen is nearly inert. It can react with Hydrogen only in atomic state. But transformation of molecular Nitrogen into atomic require a lot of energy. It looks like: molecular of Nitrogen penetrates into catalyst cavern and it terms of "Maternity Home" two free atoms of Nitrogen leave cavern and immediately joint protons (Figure 2).

That is to the point the universal and the sole mechanism [7] of any heterogeneous catalytic reactions able to explain for example universality of catalytic properties of spongy platinum in every chemical process, for the first time noticed by M. Faraday. We should also note that thanks to UQT we have obtained a number of unique results including calculation of the mass of elementary particles [9] and constant of fine structure [8]. One can find all details in book [5]. There are amazing results [10] on catalytic decomposition $\mathrm{H}_{2} \mathrm{~S}=\mathrm{H}_{2} \uparrow+\mathrm{S} \uparrow$ with separation of the heat and catalytic reaction $\mathrm{H}_{2}+\mathrm{S}=\mathrm{H}_{2} \mathrm{~S}$ also with separation of the heat! These reactions do not require any additional energy. But from the point of chemical thermodynamics that is evident infringement of the Energy Conservation Law! According to modern conception no catalyst adds any energy to the catalyzed process. But practice shows that it does! The catalyst adds energy to the process. And the only rational explanation of this fact gives new solutions for quantum oscillator in UQT. This example is not singular in the chemistry of catalysis. Specialists of catalysis are used to deal with excess heat generation; nevertheless they are "normally" ignoring this fact to avoid reputation of "ignoramus" in simple thermodynamic calculations. The role of catalyst in modern chemistry of catalysis should be revised. And that was done in [6] [7].

We should also mention the astonishing experimental results of A. Samgin and A. Baraboshkin (Russia, Institute of High-temperature Electro-Chemistry RAS, Ekaterinburg) [11] [12] and of T. Mizuno [13] (Japan). They have used, apparently independently one from each other, some special proton-conductive ceramics able to generate the thermal energy thousands time more than energy consumption if current runs through it. In some experiments of T. Mizuno that value exceeded 70,000(!). In private talk with one of the authors (L.S.) T. Mizuno said that he was worried to get sick with radiation sickness due to exposure of radiation. However no $\alpha, \beta, \gamma$ radiation or nucleus fragments were detected and, consequently, nuclear processes (fusion) were not responsible for such energy liberation. Such proton-conductive (to be more correct-deuteron-conductive) ceramics was created with of a powder metallurgy method by agglomeration at high temperature. In other words all chemical processes had finished long ago. The origin of such a great quantity of excess energy is unexplainable in the framework of usual science, because it cannot be explained either by nuclear or chemical reactions or by phase transfer. The authors of that experiment thought that reactions of nuclear fusion like $D+D$ took place. At our request A. Samgin exchanged deuterium for hydrogen in his experiments. If that great energy generation were

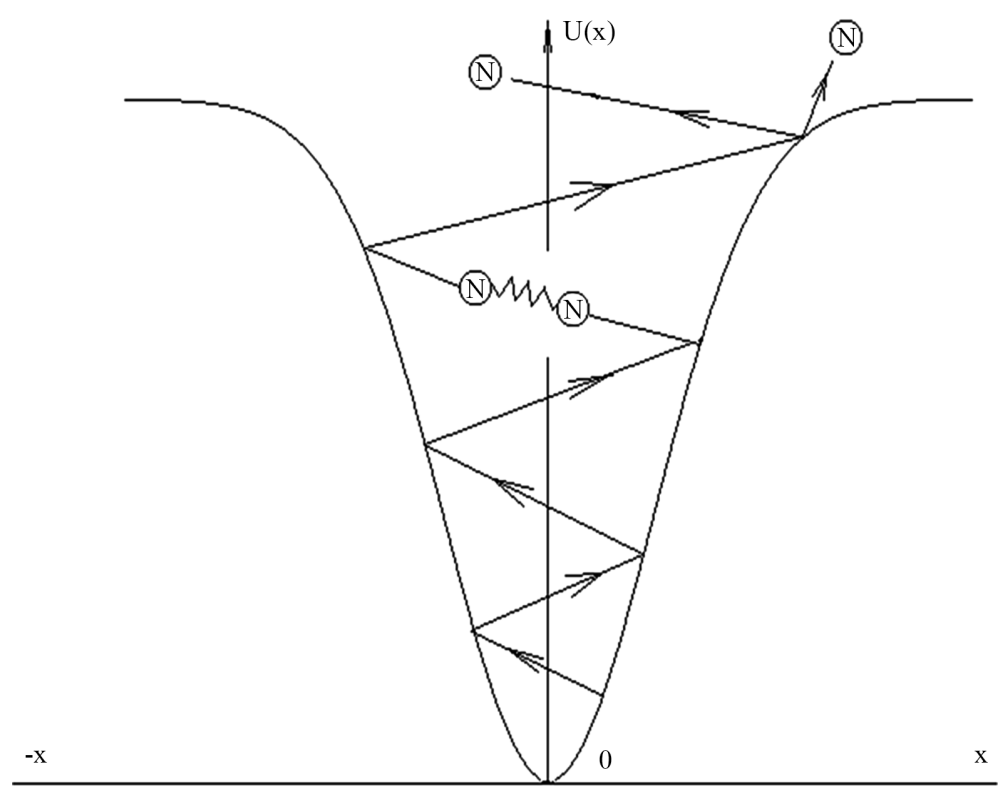

Figure 2. Oscillation of Nitrogen molecule in potential well of catalyst. 
had to do with nuclear $D-D$ reactions all anomalous heat efficiency would disappear, but it remained valid. After so great energy emission the tablet went to finest powder.

\section{Acknowledgements}

The authors thank Profs. A. S. Bogomolov, V. A. Boichenko, V. V. Graboshnikov, A. A. Kostin, M. A. Mokulsky, E. N. Maximov, V. I. Utchastkinfor useful discussion.

\section{References}

[1] Sapogin, L.G. (1973) United Field and Quantum Mechanics. System Researches (Physical Researches). Acad. Science USSR, Vladivostok, No. 2, стр. 54-84. (In Russian)

[2] Sapogin, L.G. (1979) On Unitary Quantum Mechanics. Nuovo Cimento, 53A, 251.

[3] Sapogin, L.G. (1980) An Unitary Quantum Field Theory. Annales de la Fondation Louis de Broglie, 5, 285-300.

[4] Sapogin, L.G. (2015) The Unitary Unified Quantum Field Theory. International Journal of High Energy Physics. Special Issue: Symmetries in Relativity, Quantum Theory and Unified Theories, 2, 8-32.

[5] Sapogin, L.G., Ryabov, Yu.A. and Boichenko, V.A. (2015) The Unitary Quantum Theory and a New Sources of Energy. Science Publishing Group, USA. http://www.sciencepublishinggroup.com

[6] Sapogin, L.G. and Ryabov, Yu.A. (2011) Equations with Oscillating Charge in Unitary Quantum Theory. Applied Physics Research, 3, 12-38. www.ccsenet.org/apr http://dx.doi.org/10.5539/apr.v3n2p12

[7] Sapogin, L.G. and Ryabov, Yu.A. (2011) Unitary Quantum Theory and Catalytic Process Theory. International Journal of Pure and Applied Sciences and Technology, 3, 93-120. www.ijopaasat.in

[8] Sapogin, L.G. and Boichenko, V.A. (2015) Fundamental Equation, Commutation Relations and Relativistic Invariance at Unitary Quantum Theory. International Journal of High Energy Physics. Special Issue: Symmetries in Relativity, Quantum Theory and Unified Theories, 2, 59-70.

[9] Sapogin, L.G. and Ryabov, Yu.A. (2016) The Mass Spectrum of Elementary Particles in Unitary Quantum Theory and Standard Model. Global Journal of Science Frontier Research A, 16, Version 1.0.

[10] Startsev, A.N., Kruglyakova, O.V., Chesalov, Yu.A., Ruzankin, S.Ph., Kravtsov, E.A., Larina, T.V. and Paukshtis, E.A. (2013) Low Temperature Catalytic Decomposition of Hydrogen Sulfide into Hydrogen and Diatomic Gaseous Sulfur. Topics in Catalysis, 56, 969-980. http://dx.doi.org/10.1007/s11244-013-0061-y

[11] Samgin, A., Baraboshkin, A., et al. (1994) The Influence of Conductivity on Neutron Generation Process in Proton Conducting Solid Electrolytes. In: Proceedings of the 4th International Conference on Cold Fusion, Palo Alto, Vol. 3, 51-57.

[12] Samgin, A. (1995) Cold Fusion and Anomalous Effects in Deuteron Conductors during Stationary High-Temperature Electrolysis. Proceedings of the 5th International Conference on Cold Fusion, Monte-Carlo, 9-13 April 1995, 201.

[13] Mizuno, T., Enio, M., Akimoto, T. and Azumi, K. (1993) Anamalous Heat Evolution from SrCeO3-Type Proton Conductors during Absorbtion/Desorbtion of Deuterium in Alternate Electric Field. Proceedings of the 4th International Conference on Cold Fusion, Hawaii, 6-9 December 1993, Vol. 2, 14.

\section{Submit or recommend next manuscript to OALib Journal and we will provide best service for you:}

- Publication frequency: Monthly

- 9 subject areas of science, technology and medicine

- Fair and rigorous peer-review system

- Fast publication process

- Article promotion in various social networking sites (LinkedIn, Facebook, Twitter, etc.)

- Maximum dissemination of your research work

Submit Your Paper Online: $\underline{\text { Click Here to Submit }}$

Contact Us: service@oalib.com 